\title{
Validação dos Sistemas VIÇOSA, CNCPS e NRC para Formulação de Dietas para Bovinos Nelore e Caracu, Não-Castrados, Selecionados em Condições Brasileiras ${ }^{1}$
}

\section{Antonio Gesualdi Júnior ${ }^{2}$, Augusto César de Queiroz ${ }^{3}$, Flávio Dutra de Resende ${ }^{4}$, Rogério de Paula Lana ${ }^{3}$, Ana Cristina Ladeira de Souza Gesualdi ${ }^{5}$, Guilherme Fernando Alleoni ${ }^{6}$, Edenio Detmann $^{3}$, Alexander George Razook ${ }^{7}$, Leopoldo Andrade de Figueiredo ${ }^{7}$}

RESUMO - Foram avaliados os sistemas VIÇOSA, CNCPS e NRC para formulação de dietas, utilizando-se 22 bovinos (oito Nelore, oito Caracu selecionados e seis Nelore não-selecionados) confinados com média de 18 meses de idade e peso vivo inicial médio de $404 \mathrm{~kg}$, para Nelore selecionado, $345 \mathrm{~kg}$, para Nelore não-selecionado, e $434 \mathrm{~kg}$, para Caracu. A dieta apresentou relação volumoso:concentrado de 50:50, contendo silagem de milho como volumoso. O critério de abate foi determinado pela medida de ultra-som quando os animais atingiam $4 \mathrm{~mm}$ de espessura de gordura subcutânea. Utilizou-se o teste T de Student, comparando-se as médias observadas dos grupos genéticos para os consumos de matéria seca (CMS) e ganhos médios diários (GMD) e aquelas preditas pelos sistemas VIÇOSA, CNCPS e NRC. O sistema VIÇOSA apresentou boas estimativas para os GMD de animais Nelore selecionados e não-selecionados, mas os valores diferiram do observado para a raça Caracu. Não houve boa estimativa para CMS de nenhum grupo genético, com o uso do sistema VIÇOSA. O CNCPS, níveis 1 e 2, foi eficiente para as estimativas dos CMS dos três tipos genéticos, sendo que os GMD diferiram estatisticamente do observado tanto no nível 1 quanto no 2, pois os valores foram subestimados. Apenas o nível 2 do NRC apresentou valores preditos semelhantes aos observados tanto para CMS quanto para GMD.

Palavras-chave: consumo, formulação de ração, ganho de peso, Nelore selecionado

\section{Validation of VIÇOSA, CNCPS and NRC Systems of Diets Formulation for Genetic Improved Nellore and Caracu Bulls for Brazilian Conditions}

\begin{abstract}
Twenty-two animals, eight from genetic improved Nellore breed, six non-improved Nellore and eight from genetic improved Caracu breed, were used to evaluate and to validate the VIÇOSA, CNCPS (level 1 and 2) and NRC (level 1 and 2) systems, for diet formulations. The animals were confined with average live weight of $404 \mathrm{~kg}$ to genetic improved Nellore, $345 \mathrm{~kg}$ to non-improved Nellore and $434 \mathrm{~kg}$ to genetic improved Caracu breed, all with 18 months of age. The forage used was corn silage in forage to concentrate ratio of 50:50 in the diet. The slaughter criterion was determined by ultra-sound and it was executed when the animals reached an average of four millimeters of subcutaneous fat. The Student $t$ test was used to compare the dry matter intake (DMI) and average daily gain (ADG) observed in the genetic groups and those predicted by the VIÇOSA, CNCPS and NRC systems. The VIÇOSA system showed a good estimate for ADG of the animals of genetic improved Nellore and non-improved Nellore breed, but the values were different of observed to improved Caracu. The VIÇOSA system does not have a good estimate for DMI for none of the three genetic groups. The CNCPS system, level 1 and 2 was efficient to estimate the DMI of the three genetic groups; however the estimative for ADG differed from the observed for both level 1 and level 2 of the system and the values were underestimated. In the NRC system, only the level 2 showed predicted values similar to those observed for both DMI and ADG.
\end{abstract}

Key Words: diets formulation, intake, selected Nellore, weight gain

\section{Introdução}

A análise bromatológica dos alimentos e o conhecimento da quantidade de cada nutriente potencialmente utilizável pelo animal constituem a base dos atuais sistemas de formulação de dietas para bovinos.
O sistema Cornell - Cornell Net Carbohydrate and Protein System (CNCPS) (Fox et al., 1992) adotou o fracionamento dos carboidratos e proteínas, que, associados a estimativas da dinâmica do processo, pode predizer com maior precisão a performance dos animais e estimar a quantidade de proteína microbiana

\footnotetext{
1 Parte da tese de Doutorado do primeiro autor, realizada no APTA - SP e UFV - MG. Projeto financiado pela FAPESP

2 Zootecnista, DS, Parque de Alta Tecnologia do Norte Fluminense - TECNORTE - Av. Alberto Lamego, 2000, Campos dos Goytacazes - RJ, CEP: 28013-602. E.mail: anaton@uenf.br

3 Professor do DZO - UFV, Av. PH Rolfs, Viçosa - MG, CEP: 36571-000. E.mail: aqueiroz@ufv.br; rlana@ufv.br; detmann@ufv.br

${ }^{4}$ Pesquisador da APTA Regional Alta Mogiana, Av. Rui Barbosa snº, Colina-SP, CEP: 14770-000. E.mail: flavio@aptaregional.sp.gov.br

5 Zootecnista, Estudante de Doutorado do LZNA/UENF, Campos dos Goytacazes - RJ, CEP: 28013-602. E.mail: tina@uenf.br

${ }_{7}^{6}$ Pesquisador do Instituto de Zootecnia, rua Heitor Penteado 56 centro, Nova Odessa. CEP: 13460-000, CxPO: 60. E.mail: alleoni@izsp.br

${ }^{7}$ Pesquisador do Instituto de Zootecnia, CAPTA Bovinos de Corte, Sertãozinho-SP. E.mail: razook@izsp.gov.br
} 
sintetizada e o escape ruminal de nutrientes. Com isso, determina-se energia e proteína metabolizável a partir dos dados relativos às frações de carboidratos e proteínas e de suas taxas de degradação.

Por outro lado, o sistema VIÇOSA de Formulação de Rações (Lana, 2000) possui tabelas de composição de alimentos, recomendações de uso em rações e avaliação de dietas e suplementos minerais para atender aos requerimentos nutricionais de bovinos, necessitando, assim como os demais, ser avaliado em condições nacionais.

O NRC (1996) também utiliza o fracionamento da proteína e carboidratos dos alimentos, a exemplo do CNCPS, porém estes dois sistemas são oriundos de países de clima temperado e utilizam tabelas cujos alimentos apresentam composição química distinta daqueles existentes no Brasil. Outro aspecto é que, tanto para o CNCPS quanto para o NRC, as exigências dos animais estão baseadas em raças britânicas, portanto, precoces em maturação e com peso de abate ideal fixado em $450 \mathrm{~kg}$, sendo os demais grupos genéticos avaliados por intermédio de fatores de correção para exigências nutricionais em relação ao padrão pré-definido. Dessa forma, além do estudo da composição dos alimentos, a avaliação de raças e cruzamentos de bovinos criados no Brasil é importante para a evolução de sistemas nacionais de formulação de dietas.

Segundo Nardon (1998), o melhoramento genético dos bovinos de corte praticado em nosso meio, busca o maior peso do animal em determinada idade. A seleção de bovinos com base no peso aos 378 dias de idade (P378), como realizada na Estação Experimental de Sertãozinho, mostra uma mudança genética total estimada de $46,4 \mathrm{~kg}$ no P378, para o rebanho Nelore selecionado, considerando-se 15 anos de progênies (Razook, 1998). Estes aumentos no P378 refletiram em uma série de transformações ocorridas na bioquímica, fisiologia e endocrinologia do animal. Conseqüentemente, ocorreram alterações na deposição de músculo na carcaça ou de outros tecidos que compõem o corpo do animal, ocasionando modificações nas exigências nutricionais em função do peso de corpo vazio.

Desta forma, objetivou-se, com o presente estudo, avaliar e validar os sistemas VIÇOSA, CNCPS e NRC para formulação de dietas para bovinos selecionados em condições brasileiras.

\section{Material e Métodos}

O trabalho foi conduzido na Estação Experimental de Zootecnia de Colina, unidade pertencente ao Instituto de Zootecnia, localizada na região Norte do Estado de São Paulo, numa altitude média de 589 metros, latitude sul de $20^{\circ} 43^{\prime} 5^{\prime \prime}$ e longitude oeste de $48^{\circ} 32^{\prime} 38^{\prime}$ '. O clima é classificado, segundo Koppen, como AW, caracterizado como tropical úmido, com estação chuvosa de outubro a março e seca de abril a setembro. Segundo dados da Estação Experimental, nos últimos anos, de outubro a maio, houve precipitação média mensal de $1222 \mathrm{~mm}$, correspondendo a $93,7 \%$ do total anual, enquanto, de junho a setembro, de $82 \mathrm{~mm}$, representando 6,3\%. A temperatura média do mês mais quente foi superior aos $22^{\circ} \mathrm{C}$ e do mês mais frio, superior aos $18^{\circ} \mathrm{C}$.

O solo local é classificado como latossolo vermelho escuro, fase arenosa, com topografia quase plana e de boa drenagem.

Foram utilizados 22 animais experimentais nãocastrados da 19a progênie dos rebanhos Nelore e Caracu, submetidos à seleção com base no peso aos 378 dias de idade (P378), ao final da prova de ganho de peso (PGP) para os machos. Utilizou-se, ainda, animais não-castrados do rebanho Nelore não-selecionado. Todos os rebanhos foram criados na Estação Experimental de Zootecnia de Sertãozinho/IZ.

Antes do período de adaptação, os animais foram pesados, identificados com brincos, tratados contra ecto e endoparasitas e, durante o período de adaptação (28 dias), foram alimentados à vontade com a mesma ração fornecida no período experimental. Após o período de adaptação, foram submetidos ao ensaio de alimentação, sendo distribuídos nas baias, individualmente por raça. Durante o experimento, os animais de cada grupo genético - oito Nelore selecionados $(\mathrm{NeS})$, seis Nelore não-selecionados $(\mathrm{NeN})$ e oito Caracu selecionados $(\mathrm{CaS})$ - receberam alimentação à vontade até o abate.

No início do experimento, realizou-se foi feito a pesagem inicial dos animais, em jejum completo de 18 horas, e a avaliação da condição corporal via ultrasom e do escore corporal. O período experimental iniciou-se em junho de 2001 e teve duração marcada pelo tempo de acabamento dos animais. Desse modo, quando atingiram no mínimo quatro milímetros de espessura de gordura, avaliada pelo ultra-som, foram 
abatidos. $\mathrm{O}$ abate do último grupo de animais ocorreu em setembro do mesmo ano, ou seja, 2001.

Para avaliação por meio da ultra-sonografia, os animais foram contidos em um tronco equipado com tesoura para apreensão da cabeça. O sítio anatômico para medida ultra-sônica da área de olho de lombo e espessura de gordura subcutânea foi entre a $12^{\mathrm{a}}$ e a $13^{\text {a }}$ costelas. Para o peso final no dia do abate, os animais foram submetidos a jejum completo de 18 horas, efetuando-se a pesagem no início do período de adaptação e a cada 28 dias. Em todas as pesagens, foram efetuadas as medidas de ultra-som e a avaliação do escore corporal.

A dieta foi balanceada com silagem de milho, milho moído, farelo de algodão, uréia, monensina e mistura mineral, apresentando relação volumoso:concentrado de 50:50, sendo avaliada para energia e proteína pelo sistema CNPCS, versão 4.0. O teor de nutrientes digestíveis totais (NDT) de 79\% na matéria seca (MS) foi obtido pela equação NDT $=($ Proteína Dieta - Proteína fezes $)$ + (Carboidratos Dieta - Carboidratos Fezes) + 2,25 x (Gordura Dieta - Gordura Fezes) (Sniffen et al., 1992). O teor de energia metabolizável encontrado foi de 2,85 $\mathrm{Mcal} / \mathrm{kg}$ MS. A dieta foi reajustada semanalmente com base no consumo de MS e da porcentagem de MS do volumoso e do concentrado, sendo fornecida em duas refeições diárias, às 7 e 16 h. O consumo de alimento foi controlado diariamente, procurando-se manter as sobras em torno de 5\% do oferecido para os animais.

Amostras dos alimentos oferecidos e das sobras foram coletadas semanalmente para formação de amostras compostas a cada quatro semanas, para análise bromatológica.

Foram determinados os teores de umidade, proteína bruta, extrato etéreo, fibra em detergente neutro, fibra em detergente ácido, lignina e cinzas, conforme metodologias descritas por Silva \& Queiroz (2002).

A metodologia utilizada para o fracionamento do nitrogênio foi realizada conforme descrito por Licitra et al. (1996). Os valores para degradação ruminal utilizados para as frações nitrogenadas foram obtidos de Malafaia (1997).

Para o fracionamento dos carboidratos, foram empregadas as metodologias descritas por Sniffen et al. (1992) e Van Soest et al. (1991); a técnica de incubação ruminal e produção de gases foi a mesma descrita por Malafaia (1997), obtendo-se as taxas de degradação ruminal dos carboidratos fibrosos e não-fibrosos.
A proporção dos ingredientes na mistura do concentrado é apresentada na Tabela 1.

Os teores de nutrientes do concentrado e da silagem de milho, o fracionamento e as taxas de degradação dos ingredientes são apresentados na Tabela 2.

Os dados utilizados como entrada nos sistemas de formulação CNCPS e NRC encontram-se na Tabela 3 e aqueles utilizados no sistema VIÇOSA, na Tabela 4.

Os sistemas CNCPS e NRC não possuem Caracu em sua lista de raças, portanto para este tipo genético foi utilizada a raça Shorthorn, que, segundo Minish \& Fox, 1982, citados por Barbosa (1995), é classificada da mesma forma que a raça Caracu, de acordo com o grau de musculatura e o tamanho médio à maturidade.

Foi utilizado o teste $\mathrm{T}$ de Student, no qual as médias observadas foram comparadas com os valores preditos pelos sistemas CNCPS, VIÇOSA e NRC. Constituiu-se a hipótese de nulidade sob a estrutura Ho: $\mathrm{m}=\mathrm{C}$, em que $\mathrm{C}$ representa uma constante pressuposta semelhante às estimativas fornecidas pelos diferentes sistemas avaliados. Desse modo, adotou-se a hipótese alternativa Ho: $\mathrm{m} \neq \mathrm{C}$ e $\mathrm{a}=0,10$.

Tabela 1 - Proporção dos ingredientes na mistura do concentrado

Table 1 - Ingredients percentage in concentrate mixture

\begin{tabular}{|c|c|}
\hline $\begin{array}{l}\text { Ingrediente } \\
\text { Ingredient }\end{array}$ & $\begin{array}{l}\text { Ingrediente na mistura } \\
\text { Ingredient in mixture }\end{array}$ \\
\hline Fubá de milho (\%) & 79,18 \\
\hline Ground corn (\%) & \\
\hline Farelo de algodão (\%) & 17,18 \\
\hline Cottonseed meal (\%) & \\
\hline $\begin{array}{l}\text { Uréia }(\%) \\
\text { Urea }(\%)\end{array}$ & 1,88 \\
\hline $\begin{array}{l}\text { Monensina }(\%) \\
\text { Monensin }(\%)\end{array}$ & 0,054 \\
\hline $\begin{array}{l}\text { Calcário calcítico }(\%) \\
\text { Limestone }(\%)\end{array}$ & 0,99 \\
\hline $\begin{array}{l}\text { Sal comum }(\%) \\
\text { Salt }(\%)\end{array}$ & 0,70 \\
\hline $\begin{array}{l}\text { Sulfato de zinco }(\mathrm{g} / 100 \mathrm{~kg}) \\
\text { Zinc sulfate }(\mathrm{g} / 100 \mathrm{~kg})\end{array}$ & 13,24 \\
\hline $\begin{array}{l}\text { Selenito de sódio }(\mathrm{g} / 100 \mathrm{~kg}) \\
\text { Sodium selenite }(\mathrm{g} / 100 \mathrm{~kg})\end{array}$ & 0,034 \\
\hline $\begin{array}{l}\text { Sulfato de manganês }(\mathrm{g} / 100 \mathrm{~kg}) \\
\text { Manganese sulfate }(\mathrm{g} / 100 \mathrm{~kg})\end{array}$ & 6,24 \\
\hline
\end{tabular}


Tabela 2 - Teores de matéria seca (MS), matéria orgânica (MO), proteína bruta (PB), fibra em detergente neutro (FDN), fibra em detergente neutro corrigido para cinzas e proteína (FDNcp), carboidratos totais (CHOT), carboidratos não-fibrosos (CNF), extrato etéreo (EE) e matéria mineral (MM) do concentrado e da silagem de milho, fracionamento e taxas de degradação dos carboidratos e proteínas dos ingredientes da dieta

Table 2 - Contents of dry matter (DM), organic matter (OM), crude protein (CP), neutral detergent fiber (NDF), neutral detergent fiber corrected for ash and protein (NDFap), total carbohydrates (TC), nonfiber carbohydrates (NFC), ether extract (EE) and mineral matter (MM) of concentrate and corn silage, fractions and rates of degradation of carbohydrates and protein of diet ingredients

\begin{tabular}{|c|c|c|c|c|}
\hline $\begin{array}{l}\text { Nutriente } \\
\text { Nutrient }\end{array}$ & $\begin{array}{c}\text { Mistura concentrada } \\
\text { Concentrate mixture }\end{array}$ & $\begin{array}{c}\text { Farelo de algodão } \\
\text { Cottonseed meal }\end{array}$ & $\begin{array}{c}\text { Fubá de milho } \\
\text { Ground corn }\end{array}$ & $\begin{array}{l}\text { Silagem de milho } \\
\text { Corn silage }\end{array}$ \\
\hline $\operatorname{MS}(\%)(D M)$ & 81,70 & 81,94 & 79,57 & 27,14 \\
\hline $\mathrm{PB}^{1}(C P)$ & 18,81 & 34,40 & 9,46 & 8,82 \\
\hline $\mathrm{FDN}^{1}(N D F)$ & 15,98 & 36,96 & 12,56 & 60,92 \\
\hline $\mathrm{FDNcp}^{1}$ (NDFap) & 13,97 & 33,98 & 11,06 & 57,69 \\
\hline $\mathrm{EE}^{1}(E E)$ & 3,81 & 4,18 & 3,03 & 2,25 \\
\hline $\mathrm{MM}^{1}(M M)$ & - & 5,50 & 1,45 & 4,40 \\
\hline
\end{tabular}

Fracionamento protéico (\% PB)

Protein fraction (\% CP)

$\begin{array}{lcccc}\text { A } & - & 6,67 & 11,84 & 35,47 \\ \text { B1 } & - & 5,10 & 5,41 & 9,13 \\ \text { B2 } & - & 82,10 & 73,04 & 30,88 \\ \text { B3 } & - & 0,85 & 2,70 & 15,71 \\ \text { C } & - & 5,29 & 7,01 & 8,81\end{array}$

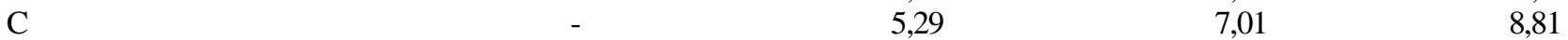

Taxa de degradação $(\% / \mathrm{h})$

Degradation rate $(\% / h)$

$\begin{array}{lcccc}\mathrm{B}^{2} & - & 186,66 & 50,18 & 94,11 \\ \mathrm{~B}^{2} & - & 9,86 & 2,94 & 1,47 \\ \mathrm{~B}^{2} & - & 0,23 & 0,23 & 0,21\end{array}$

Fracionamento de carboidrato (\% CHOT)

Carbohydrate fraction (\% TC)

$\begin{array}{lcccr}\text { A+B1 } & - & 66,02 & 88,94 & 42,31 \\ \text { B2 } & - & 14,13 & 10,41 & 45,61 \\ \text { C } & - & 19,85 & 0,65 & 12,08\end{array}$

$\begin{array}{lllll}\mathrm{C} & - & 19,85 & 0,65 & 12,08\end{array}$

Taxa de degradação $(\% / \mathrm{h})$

Degradation rate $(\% / h)$

\begin{tabular}{lcccc}
$\mathrm{SDN}^{3}\left(N D S^{3}\right)$ & - & 25,45 & 20,68 & 26,92 \\
$\mathrm{~B} 2$ & - & 2,47 & 2,48 & 3,02 \\
\hline
\end{tabular}

$1 \%$ na MS (\% in DM).

2 Valores obtidos de Malafaia (1997) (Values according to Malafaia, 1997).

3 Solúveis em detergente neutro (Neutral detergent soluble).

Tabela 3 - Resumo de entradas dos animais e de condições ambientais nos sistemas CNCPS e NRC, de acordo com os grupos genéticos Nelore selecionado ( $\mathrm{NeS}$ ), Nelore não-selecionado ( $\mathrm{NeN}$ ) e Caracu selecionado (CaS)

Table 3 - Summary of animal and environmental imputs in CNCPS and NRC systems, accord genetic improved Nellore (GIN), genetic non-improved Nellore (GNIN) and genetic improved Caracu (GIC)

\begin{tabular}{|c|c|c|c|c|c|c|}
\hline \multirow[b]{2}{*}{$\begin{array}{l}\text { Grupo } \\
\text { genético } \\
\text { Genetic } \\
\text { group }\end{array}$} & \multicolumn{6}{|c|}{ CNCPS e NRC } \\
\hline & $\begin{array}{l}\text { Idade de abate } \\
\text { (meses) } \\
\text { Slaughter age } \\
\text { (months) }\end{array}$ & $\begin{array}{c}\text { Peso vivo } \\
\text { inicial }(\mathrm{kg}) \\
\text { Initial weight }(\mathrm{kg})\end{array}$ & $\begin{array}{c}\text { Peso maduro }(\mathrm{kg}) \\
\text { com } 28 \% \text { gordura } \\
\text { Mature weight } \\
\text { with } 28 \% \text { fat }(\mathrm{kg})\end{array}$ & $\begin{array}{l}\text { Escore }(1-9) \\
\text { Score }(1-9)\end{array}$ & $\begin{array}{l}\text { Temperatura }\left({ }^{\circ} \mathrm{C}\right) \\
\text { Temperature }\left({ }^{\circ} \mathrm{C}\right)\end{array}$ & $\begin{array}{l}\text { Umidade relativa (\%) } \\
\text { Relative humidity }(\%)\end{array}$ \\
\hline NeSGIN & 22 & 404 & 524 & 6 & 28 & 60 \\
\hline NeNGNIN & 22 & 345 & 443 & 6 & 28 & 60 \\
\hline $\mathrm{CaSGIC}$ & 22 & 434 & 566 & 6 & 28 & 60 \\
\hline
\end{tabular}


Tabela 4 - Resumo de entradas dos animais no sistema VIÇOSA, de acordo com os grupos genéticos Nelore selecionado (NeS), Nelore não-selecionado (NeN) e Caracu selecionado (CaS)

Table 4 - Summary of imputs of animals in VIÇOSA system, according to genetic improved Nellore (GIN), genetic non-improved Nellore (GNIN) and genetic improved Caracu (GIC)

\begin{tabular}{lccc}
\hline & \multicolumn{4}{c}{ VIÇOSA } \\
\cline { 2 - 4 } $\begin{array}{l}\text { Grupo genético } \\
\text { Genetic group }\end{array}$ & $\begin{array}{c}\text { Peso vivo inicial }(\mathrm{kg}) \\
\text { Initial } \text { weight }(\mathrm{kg})\end{array}$ & $\begin{array}{c}\text { Peso maduro com 28\% de gordura }(\mathrm{kg}) \\
\text { Mature weight with 28\% of fat }(\mathrm{kg})\end{array}$ & $\begin{array}{c}\text { Ganho de peso vivo esperado }(\mathrm{kg} / \mathrm{dia}) \\
\text { Expected weight gain ( } \mathrm{kg} / \text { day) }\end{array}$ \\
\hline NeSGIN & 404 & 524 & 1,200 \\
NeNGNIN & 345 & 443 & 1,050 \\
CaSGIC & 434 & 566 & 1,250 \\
\hline
\end{tabular}

\section{Resultados e Discussão}

Os consumos de matéria seca (CMS) e os ganhos médios diários de peso vivo (GMD) em $\mathrm{kg}$ /dia para os valores observados e suas estimativas, de acordo com os sistemas NRC, CNCPS e VIÇOSA, são apresentados nas Tabelas 5 e 6 .

Os valores para os CMS estimados pelo NRC nível 1 e pelo sistema VIÇOSA (Tabela 5) foram diferentes $(\mathrm{P}<0,10)$ dos observados neste estudo para os grupos genéticos $\mathrm{NeS}, \mathrm{NeN}$ e CaS. O nível 2 do NRC, assim como os níveis 1 e 2 do CNCPS, mostrouse eficiente ao predizer os CMS dos diferentes grupos genéticos $(\mathrm{P}>0,10)$. Estes resultados estão parcialmente de acordo com Capelle et al. (2001), que, ao avaliarem vários dados experimentais, encontraram adequada predição do CNCPS para CMS. Contrariando estes resultados, Véras et al. (2000) verificaram que os CMS obtidos foram maiores que os preditos para tratamentos cujos níveis de concentrado foram de $25 ; 37,5 ; 50 ; 62,5$ e $75 \%$ e não seguiram o comportamento da relação ideal, sugerindo que o CNCPS não foi adequado para predizer a ingestão de MS.

No nível 1 dos sistemas CNCPS e NRC, os valores de energia da ração são obtidos pelo somatório da contribuição de energia de cada alimento para alcançar o conteúdo total de energia da dieta, utilizando-se valores tabulares. $\mathrm{O}$ suprimento de proteína metabolizável, por sua vez, é o somatório da proteína digerível do alimento não degradada no rúmen e a proteína bacteriana digestível. Para o nível 2, computa-se os requerimentos de aminoácidos, enquanto os valores de energia e proteína são preditos a partir das propriedades físico-químicas dos alimentos (NRC, 1996). Os requerimentos de energia e proteína dos animais, são os mesmos para os dois níveis.

O ganho médio diário dos animais apresentou diferenças entre os valores observados e os preditos pelo CNCPS, níveis 1 e $2(\mathrm{P}<0,10)$, de forma similar aos de
Lanna et al. (1994), Lanna et al. (1995), Ferreira et al. (1998) e Capelle et al. (2001). Por outro lado, Brito et al. (1998) encontraram boa predição ao ajustarem a dieta de bovinos F1 Canchim x Nelore pelo CNCPS.

O sistema NRC nível 2, para os bovinos dos três grupos genéticos e o sistema VIÇOSA, para os animais $\mathrm{NeS}$ e $\mathrm{NeN}$, forneceram boas estimativas ao predizerem os GMD (Tabela 6) $(\mathrm{P}>0,10)$. Segundo o NRC (1996), o nível 2 foi idealizado para obter informação adicional sobre a utilização de carboidratos e proteínas no rúmen, além de requerimentos e suprimentos de aminoácidos. Para alcançar estes objetivos, submodelos mecanísticos (Fox et al., 1992; Russell et al., 1992; Sniffen et al., 1992) foram incorporados tanto pelo CNCPS quanto pelo NRC (1996), constituindo-se no nível 2 destes sistemas, os quais estão capacitados a predizer o crescimento microbiano a partir de frações de proteínas e carboidratos dos alimentos e de suas taxas de digestão e passagem.

Lana et al. (2001), trabalhando com um banco de dados de 18 teses, totalizando 530 bovinos em confinamento no sul do Brasil, observaram que o sistema VIÇOSA superestimou o CMS $(9,95 \%)$, corroborando as validações deste sistema no presente trabalho, mas subestimou o GMD (-4,88\%).

O CNCPS subestimou os GMD para os três grupos genéticos deste estudo $(\mathrm{P}<0,10)$. Segundo Capelle et al. (2001), a amplitude das diferenças que ocorrem entre o GMD predito e o observado pode estar relacionada à alimentação, ao grau de sangue, à idade de abate, à condição sexual e a outras características que podem ser consideradas quando se utiliza o CNCPS e outros sistemas para predizer o desempenho de bovinos. Neste contexto, Perotto et al. (2001) encontraram efeito de mês e de ano de nascimento, além de efeito de touro dentro de uma mesma raça, ao avaliarem o ganho de peso da desmama aos 12 meses e o peso aos 12 meses de idade de bovinos Nelore e cruzados. 


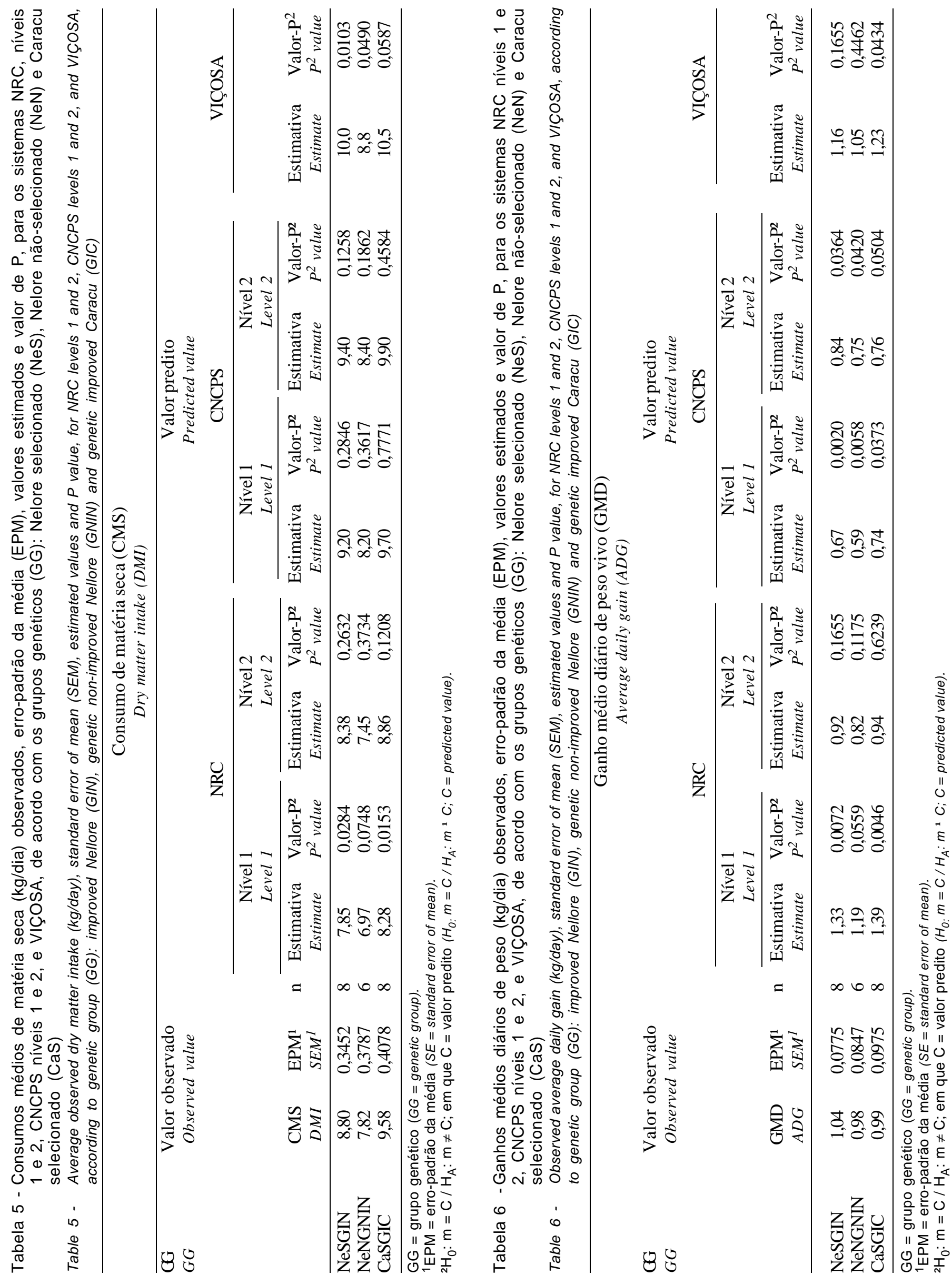


O ganho compensatório, fenômeno muito comum em rebanhos de países de clima tropical e mais raro em climas temperados, também pode contribuir para a ocorrência de simulações que subpredizem o ganho e o consumo médio esperado. Entretanto, a extensão do ganho compensatório, se nulo, parcial ou completo é de difícil predição.
A todos estes fatores determinantes do desempenho animal, acrescenta-se as possibilidades de interações, que, somadas aos efeitos de mês, ano de nascimento, possibilidade de ganho compensatório e de touro dentro de uma mesma raça, ainda não foram eficientemente incorporadas em sistemas de formulação de dietas, mas certamente influenciam os resultados obtidos a campo.

Tabela 7 - Ganhos médios diários de peso vivo observados (GMD obs) e estimados a partir da energia metabolizável (EM) e proteína metabolizável (PM) da dieta, para os sistemas CNCPS e NRC, e a partir dos nutrientes digestíveis totais (NDT) e proteína bruta (PB), para o sistema VIÇOSA

Table 7 - Observed (ADG obs) and estimated average daily gain and by using dietary metabolizable energy (ME) and metabolizable protein (MP), for CNCPS and NRC systems and by using total digestible nutrients (TDN) and crude protein (CP) for VIÇOSA system

\begin{tabular}{|c|c|c|c|}
\hline \multirow{3}{*}{$\begin{array}{l}\text { Grupo genético } \\
\text { Genetic group }\end{array}$} & \multicolumn{3}{|c|}{ CNCPS nível 1 (CNCPS level 1) } \\
\hline & GMD obs (kg/dia) & \multirow{2}{*}{\multicolumn{2}{|c|}{$\begin{array}{l}\text { GMD estimado (kg/dia) } \\
\text { Estimated } A D G(\mathrm{~kg} / \text { day })\end{array}$}} \\
\hline & Obs $A D G(k g / d a y)$ & & \\
\hline $\mathrm{NeS}^{1}(G I N)$ & 1,04 & 1,02 & 0,67 \\
\hline $\mathrm{NeC}^{2}($ GNIN) & 0,97 & 0,92 & 0,59 \\
\hline $\mathrm{CaS}^{3}(G I C)$ & 0,99 & 1,00 & 0,74 \\
\hline
\end{tabular}

\begin{tabular}{|c|c|c|c|}
\hline \multirow{3}{*}{$\begin{array}{l}\text { Grupo genético } \\
\text { Genetic group }\end{array}$} & \multicolumn{3}{|c|}{ CNCPS nível 2(CNCPS level 2 ) } \\
\hline & \multirow{2}{*}{$\begin{array}{l}\text { GMD obs (kg/dia) } \\
\text { Obs } A D G(k g / d a y)\end{array}$} & \multirow{2}{*}{\multicolumn{2}{|c|}{$\begin{array}{l}\text { GMD estimado (kg/dia) } \\
\text { Estimated } A D G(\mathrm{~kg} / \text { day })\end{array}$}} \\
\hline & & & \\
\hline $\mathrm{NeS}^{1}(G I N)$ & 1,04 & 0,84 & 1,89 \\
\hline $\mathrm{NeC}^{2}(G N I N)$ & 0,97 & 0,75 & 1,67 \\
\hline
\end{tabular}

\begin{tabular}{|c|c|c|c|}
\hline \multirow{3}{*}{$\begin{array}{l}\text { Grupo genético } \\
\text { Genetic group }\end{array}$} & \multicolumn{3}{|c|}{ NRC nível 1 (NRC level 1) } \\
\hline & \multirow{2}{*}{$\begin{array}{l}\text { GMD obs (kg/dia) } \\
\text { Obs } A D G(k g / d a y)\end{array}$} & \multirow{2}{*}{\multicolumn{2}{|c|}{$\begin{array}{l}\text { GMD estimado (kg/dia) } \\
\text { Estimated } A D G(\mathrm{~kg} / \text { day })\end{array}$}} \\
\hline & & & \\
\hline $\operatorname{NeS}^{1}(G I N)$ & 1,04 & 1,33 & 1,84 \\
\hline $\mathrm{NeC}^{2}(G N I N)$ & 0,97 & 1,19 & 1,64 \\
\hline
\end{tabular}

\begin{tabular}{|c|c|c|c|}
\hline \multirow{3}{*}{$\begin{array}{l}\text { Grupo genético } \\
\text { Genetic group }\end{array}$} & \multicolumn{3}{|c|}{ NRC nível 2 (NRC level 2 ) } \\
\hline & \multirow{2}{*}{$\begin{array}{l}\text { GMD obs }(\mathrm{kg} / \text { dia }) \\
\text { Obs } A D G(k g / \text { day })\end{array}$} & \multirow{2}{*}{\multicolumn{2}{|c|}{$\begin{array}{l}\text { GMD estimado (kg/dia) } \\
\text { Estimated } A D G(\mathrm{~kg} / \text { day })\end{array}$}} \\
\hline & & & \\
\hline $\mathrm{NeS}^{1}(G I N)$ & 1,04 & 0,92 & 2,49 \\
\hline $\mathrm{NeC}^{2}($ GNIN) & 0,97 & 0,82 & 2,21 \\
\hline $\mathrm{CaS}^{3}(G I C)$ & 0,99 & 0,94 & 2,75 \\
\hline
\end{tabular}

\begin{tabular}{|c|c|c|c|}
\hline \multirow[b]{2}{*}{$\begin{array}{l}\text { Grupo genético } \\
\text { Genetic group }\end{array}$} & \multicolumn{3}{|c|}{ Sistema VIÇOSA (VIÇOSA system) } \\
\hline & $\begin{array}{l}\text { GMD obs (kg/dia) } \\
\text { Obs } A D G(k g / \text { day })\end{array}$ & \multicolumn{2}{|c|}{$\begin{array}{c}\text { GMD estimado }(\mathrm{kg} / \mathrm{dia}) \\
\text { Estimated } A D G(\mathrm{~kg} / \text { day })\end{array}$} \\
\hline & & $\operatorname{NDT}(T D N)$ & $\mathrm{PB}(C P)$ \\
\hline $\begin{array}{l}\operatorname{NeS}^{1}(\text { GIN }) \\
\mathrm{NeC}^{2}(\text { GNIN) } \\
\operatorname{CaS}^{3}(\text { GIC })\end{array}$ & $\begin{array}{l}1,04 \\
0,97 \\
0,99\end{array}$ & $\begin{array}{l}1,16 \\
1,05 \\
1,23\end{array}$ & $\begin{array}{l}1,90 \\
1,80 \\
2,00\end{array}$ \\
\hline
\end{tabular}

\footnotetext{
${ }^{1}$ Nelore selecionado (Genetic improved Nellore).

${ }^{2}$ Nelore não-selecionado (Genetic non-improved Nellore).

${ }^{3}$ Caracu selecionado (Genetic improved Caracu).
} 
Na Tabela 7 constam os GMD observados e os estimados a partir da energia metabolizável (EM) e de proteína metabolizável (PM) da dieta, para NRC e CNCPS, e dos nutrientes digestíveis totais (NDT) e da proteína bruta (PB) da dieta, para o sistema VIÇOSA. Observou-se que a PM limitou o GMD apenas para o sistema CNCPS nível 1, subestimando ainda este ganho. Para o nível 2 deste submodelo, a EM limitou o ganho, também apresentando subestimativas.

O nível 1 do modelo NRC superestimou o GMD dos animais deste estudo e o sistema VIÇOSA superestimou o GMD dos animais CaS.

É possível que os três sistemas estudados necessitem de ajustes para avaliarem animais de alto potencial de ganho de peso em condições tropicais, em razão das sub e superestimativas do desempenho dos animais selecionados para peso aos 378 dias. Por outro lado, deve-se reconhecer que o emprego de animais selecionados em experimentos, no nível daqueles utilizados neste estudo, ainda é escasso e, portanto, as tabelas de exigências nutricionais a serem confeccionadas no futuro poderão levar em conta esta categoria a partir do aumento do uso desses animais tanto nos trabalhos de pesquisa quanto a campo.

Diante dos resultados insatisfatórios para a predição dos desempenhos dos animais, será necessário maior número de pesquisas neste sentido visando adequar os fatores empregados para as raças e os cruzamentos utilizados no Brasil. Segundo o NRC (1996), amimais zebuínos resultantes de cruzamentos requerem $10 \%$ menos de energia líquida para mantença e, para o cálculo das exigências de energia líquida para ganho de peso, é necessária a fórmula que contém o peso-padrão de referência, que pode ter os valores de 435,462 e $478 \mathrm{~kg}$ para teor de gordura final no corpo de 25,2; 26,8 e 27,8\%. Segundo Valadares Filho (1999), ao se trabalhar com animais zebuínos, deve-se observar que o pesopadrão de referência e os teores de gordura na carcaça podem ser diferentes daqueles citados nos Estados Unidos. Segundo o autor, é possível que esse peso esteja próximo de $450 \mathrm{~kg}$ e, conseqüentemente, poderiam ser obtidas algumas estimativas para zebuínos, para que, no futuro, seja possível elaborar uma tabela de requerimentos nutricionais adequada para estes animais.

\section{Conclusões}

Os sistemas NRC nível 2, para os três grupos genéticos, e VIÇOSA, para a raça Nelore, apresentaram boa predição do ganho médio diário; os valores preditos foram similares aos observados.

O sistema CNCPS não apresentou predições satisfatórias para ganho médio diário, sendo eficiente apenas para predizer consumo de matéria seca.

Os sistemas NRC nível 1 e VIÇOSA não apresentaram predições satisfatórias para consumo de matéria seca.

São necessários mais estudos no Brasil que avaliem recursos genéticos disponíveis e o nível de influência que os fatores podem exercer sobre os resultados das predições.

\section{Literatura Citada}

BARBOSA, P.F. Cruzamentos para obtenção do novilho precoce. In: ENCONTRO NACIONAL SOBRE NOVILHO PRECOCE, 1995, Campinas. Palestras... Campinas: 1995. p.75-92.

BRITO, R.M.; SAMPAIO, A.A.M.; ROSSI JR., P. et al. Comparação de sistemas de nutrição de bovinos no modelo de produção intensiva de carne. III - Desempenho em confinamento. In: REUNIÃO ANUAL DA SOCIEDADE BRASILEIRA DE ZOOTECNIA, 35., 1998, Botucatu. Anais... Botucatu: Sociedade Brasileira de Zootecnia, 1998. p.212.

CAPELLE, E.R.; VALADARES FILHO, S.C.; COELHO DA SILVA, J.F. et al. Estimativas do consumo e do ganho de peso de bovinos, em condições brasileiras. Revista Brasileira de Zootecnia, v.30, n.6, p.659-1957, 2001.

FERREIRA, M.A; VALADARES FILHO, S.C.; COELHO DA SILVA, J.F. et al. Consumo, conversão alimentar, ganho de peso e características da carcaça de bovinos $\mathrm{F}_{1}$ simental $\mathrm{x}$ nelore. Revista Brasileira de Zootecnia, v.28, n.2, p.343-351, 1998 .

FOX, D.G.; SNIFFEN, C.J.; O'CONNOR, J.D. et al. A net carbohydrate and protein system for evaluating cattle diets. III. Cattle requirements and diets adequacy. Journal of Animal Science, v.70, n.11, p.3578-3596, 1992.

LANA, R.P. Sistema Viçosa de formulação de rações. Universidade Federal de Viçosa. Viçosa, MG, 2000. 60p.

LANA, R.P.; EIFERT, E.C.; OLIVEIRA, M.V.M. Validação do sistema VIÇOSA de formulação de rações para bovinos de corte em confinamento. In: REUNIÃO ANUAL DA SOCIEDADE BRASILEIRA DE ZOOTECNIA, 38., 2001, Piracicaba. Anais... Piracicaba: Sociedade Brasileira de Zootecnia, 2001. p.1195.

LANNA, D.P.D.; BOIN, C.; FOX, D.G. Utilização do CNCPS para estimativa do desempenho animal e do valor nutricional do bagaço de cana tratado a pressão de vapor. In: REUNIÃO ANUAL DA SOCIEDADE BRASILEIRA DE ZOOTECNIA, 31., 1994, Maringá. Anais... Maringá: Sociedade Brasileira de Zootecnia, 1994. p.478. 
LANNA, D.P.D.; BOIN, C.; FOX, D.G. Exigências de proteína de tourinhos em crescimento alimentados com dietas a base bagaço de cana hidrolisado. In: REUNIÃO ANUAL DA SOCIEDADE BRASILEIRA DE ZOOTECNIA, 32, 1995, Brasília. Anais... Brasília: Sociedade Brasileira de Zootecnia, 1995. p.187.

LICITRA, G.; HERNANDEZ, T.M.; Van SOEST, P.J. Standardization of procedures for nitrogen fractionation of ruminant feeds. Animal Feed Science Technology, v.57, n.4, p.347-358, 1996.

MALAFAIA, P.A.M. Taxas de digestão das frações protéicas e de carboidratos de alimentos por técnica in situ, in vitro e de produção de gases. Viçosa, MG: Universidade Federal de Viçosa, 1997. 89p. Tese (Doutorado em Zootecnia) Universidade Federal de Viçosa, 1997.

NARDON, R.F. Seleção de bovinos para desempenho: composição corporal e características de carcaça. Jaboticabal: Universidade Estadual Paulista, 1998. 99p. Tese (Doutorado em Zootecnia) - Universidade Estadual Paulista, 1998.

NATIONAL RESEARCH COUNCIL - NRC. Nutrients requeriments of beef cattle. 7.ed. Washington, D.C.: 1996. $244 \mathrm{p}$.

PEROTTO, D.; CUBAS, A.C.; ABRAHÃO, J.J.S. et al. Ganho de peso da desmama aos 12 meses e peso aos 12 meses de bovinos nelore e cruzas com nelore. Revista Brasileira de Zootecnia, v.30, n.4, p.730-734, 2001.

RAZOOK, A.G. et al. Selection for yearling weight in Nelore and Guzerá zebu breeds: Selection applied and response in 15 years of progeny. In: WORLD CONGRESS ON GENETIC APPLIED TO LIVESTOCK PRODUCTION, 6., 1998, Armidale. Proceedings... Armidale: 1998. p.133-136.
RUSSEL, J.B.; O'CONNOR, J.D.; FOX, D.G. et al. A net carbohydrate and protein system for evaluating cattle diets: I. Ruminal fermentation. Journal of Animal Science, v.70, n.11, p.3551-3561, 1992.

SILVA, D.J.; QUEIROZ, A.C. Análise de alimentos (métodos químicos e biológicos). 3.ed. Viçosa, MG: Universidade Federal de Viçosa, 2002. 235p.

SNIFFEN, C.J.; O'CONNOR, J.D.; Van SOEST, P.J. et al. A net carbohydrate and protein system for evaluating cattle diets: II. Carbohydrate and protein availability. Journal of Animal Science, v.70, n.11, p.3562-3577, 1992.

VALADARES FILHO, S.C. Padrões de alimentação: fundamentos e programas para cálculo de ração. In: I SIMPÓSIO DE PRODUÇÃO DE GADO DE CORTE, 1999, Viçosa, MG. Anais... Viçosa, MG: Universidade Federal de Viçosa, 1999. p. 157.

Van SOEST, P.J.; ROBERTSON, J.B.; LEWIS, B.A. Symposium: carbohydrate methodology, metabolism, and nutritional implications in dairy cattle. Journal of Dairy Science, v.74, n.10, p.3583-3597, 1991.

VÉRAS, A.S.C.; VALADARES FILHO, S.C.; COELHO DA SILVA, J.F. et al. Consumo e digestibilidade aparente em bovinos nelore, não castrados, alimentados com rações contendo deferentes níveis de concentrado. Revista Brasileira de Zootecnia, v.29, n.6, p.2367-2378, 2000.

Recebido em: 20/07/04

Aceito em: 24/01/05 